\title{
Retraction Note to: Methylene blue photochemical treatment as a reliable SARS-CoV-2 plasma virus inactivation method for blood safety and convalescent plasma therapy for COVID-19
}

\author{
Changzhong $\mathrm{Jin}^{1 \dagger}$, Bin $\mathrm{Yu}^{2^{*}+}$, Jie Zhang ${ }^{3+}$, Hao Wu${ }^{2}$, Xipeng Zhou ${ }^{2}$, Hangping Yao ${ }^{1}$, Fumin Liu', Xiangyun Lu', \\ Linfang Cheng ${ }^{1}$, Miao Jiang ${ }^{2^{*}}$ and Nanping $\mathrm{Wu}^{1 *}$
}

Retraction Note: BMC Infect Dis 21, 357 (2021) https://doi.org/10.1186/s12879-021-05993-0

The editor has retracted this article. Following publication concerns were raised regarding Fig. 1, specifically:

- The Light 0 min panel for Virus Control appears to partially overlap with the Light 0 min panel for $1 \mathrm{uM}$ MB No light.

- The Light 0 min panel for 1um MB No light appears to partially overlap with the Light 40 Min panel of the same row, and partially overlap with the Light 0 Min panel for No MB.

In addition, the authors Bin $\mathrm{Yu}$, Jie Zhang, Hao Wu, Xipeng Zhou and Miao Jiang did not appropriately declare a competing interest regarding their affiliation with Boxin (Beijing) Biotechnology Development LTD and its

\footnotetext{
The original article can be found online at https://doi.org/10.1186/s12879021-05993-0.

*Correspondence: yubin@boxinbio.com; jiangmiao@boxinbio.com; flwnp2013@163.com

${ }^{\dagger}$ Changzhong Jin, Bin Yu and Jie Zhang contributed equally to this work. ${ }^{2}$ Boxin (Beijing) Biotechnology Development LTD, 4/F, Tower B, Siemens Building, No. 7 South Central Road, Wangjing, Chaoyang District, Beijing, China

${ }^{1}$ State Key Laboratory for Diagnosis and Treatment of Infectious Diseases, National Clinical Research Center for Infectious Disease, National Medical Center for Infectious Disease, Collaborative Innovation Center for Diagnosis and Treatment of Infectious Diseases, The First Affiliated Hospital, School of Medicine, Zhejiang University, Hangzhou 310003, China

Full list of author information is available at the end of the article
}

product 'BX-1 AIDS treatment instrument' as described in this article.

The editor therefore no longer has confidence in the reliability of the data reported in the article.

Changzhong Jin, Bin $\mathrm{Yu}$, Jie Zhang, Hangping Yao, Fumin Liu, Xiangyun Lu, Linfang Cheng, Miao Jiang and Nanping Wu do not agree to this retraction. Hao Wu and Xipeng Zhou have not responded to any correspondence from the editor about this retraction.

\begin{abstract}
Author details
${ }^{1}$ State Key Laboratory for Diagnosis and Treatment of Infectious Diseases, National Clinical Research Center for Infectious Disease, National Medical Center for Infectious Disease, Collaborative Innovation Center for Diagnosis and Treatment of Infectious Diseases, The First Affiliated Hospital, School of Medicine, Zhejiang University, Hangzhou 310003, China. ${ }^{2}$ Boxin (Beijing) Biotechnology Development LTD, 4/F, Tower B, Siemens Building, No. 7 South Central Road, Wangjing, Chaoyang District, Beijing, China. ${ }^{3}$ Ministry of Education Key Lab of Hazard Assessment and Control in Special Operational Environment, Preventive Medicine Institute, Air force Medical University, Xi'an, China
\end{abstract}

Published online: 09 July 2021

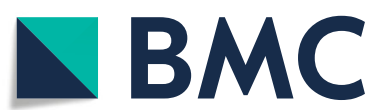

(c) The Author(s). 2021 Open Access This article is licensed under a Creative Commons Attribution 4.0 International License, which permits use, sharing, adaptation, distribution and reproduction in any medium or format, as long as you give appropriate credit to the original author(s) and the source, provide a link to the Creative Commons licence, and indicate if changes were made. The images or other third party material in this article are included in the article's Creative Commons licence, unless indicated otherwise in a credit line to the material. If material is not included in the article's Creative Commons licence and your intended use is not permitted by statutory regulation or exceeds the permitted use, you will need to obtain permission directly from the copyright holder. To view a copy of this licence, visit http://creativecommons.org/licenses/by/4.0/ The Creative Commons Public Domain Dedication waiver (http://creativecommons.org/publicdomain/zero/1.0/) applies to the data made available in this article, unless otherwise stated in a credit line to the data. 